\title{
RISK ANALYSIS IN OCCUPATIONAL HEALTH AND SAFETY APPLICATIONS: A CASE STUDY OFA CARGO FIRM
}

DOI: 10.17261/Pressacademia.2018.901

PAP- V.7-2018(54)-p.295-299

Mehmet Colak ${ }^{1}$, Onur Sanli², Tahsin Cetin ${ }^{3}$

${ }^{1}$ Mugla Sitki Kocman University, Technology Faculty, Woodworking Industrial Engineering, 48000, Kotekli Campus, Mugla, Turkey. cmehmet@mu.edu.tr, ORCID: 0000-0003-4780-587X

${ }^{2}$ Mugla Sitki Kocman University, Technology Faculty, Woodworking Industrial Engineering, 48000, Kotekli Campus, Mugla, Turkey. sanlionur67@gmail.com, ORCID: 0000-0002-0866-7083

${ }^{3}$ Mugla Sitki Kocman University, Technology Faculty, Woodworking Industrial Engineering, 48000, Kotekli Campus, Mugla, Turkey. tahsincetin@mu.edu.tr, ORCID: 0000-0002-7886-981X

To cite this document

Colak, M., Sanli, O., Cetin, T. (2018). Risk analysis in occupational health and safety applications: a case study of a cargo firm. PressAcademia Procedia (PAP), V.7, p.295-299.

Permemant link to this document: http://doi.org/10.17261/Pressacademia.2018.901

Copyright: Published by PressAcademia and limited licenced re-use rights only.

\section{ABSTRACT}

Purpose- Firms are obliged to provide quality service in compliance with storage, shipment, and other needs in order to compete in the market conditions, also they are obliged to ensure the safety of employees and products.

Methodology- In this study; it is aimed to test the applications that can be applied in the cargos sector, to create risk analyzes and to emphasize the necessity and importance of occupational health and safety analysis according to these results.

Findings- There are the risk of people falling from the ramp during the loading and unloading process and the tipping over of raw material during or after the loading into the pallet ramp. In addition, during loading and unloading operations, if necessary precautions are not taken in terms of occupational and worker saferty during these works, it damages the worker and warehousing products.

Conclusion- When the risks are taken into consideration, cargos companies should perform risk analysis to ensure that hazards and problems will ocur. In this context, it is needed to provide and implement training on occupational health and safety regularly in order to protect against the identified risks. Periodic evaluations are performed at regular intervals that decrease in loss of life and property at cargos companies, both tangible as well as intangible losses will be reduced.

Keywords: Occupationa health and safety, cargo, risk assestment, transportation, strorage.

JEL Codes: I10, I11, L00

\section{iş SAĞLIĞı VE iŞ GÜVENLiĞi UYGULAMALARINDA RISK ANALIZi (BíR KARGO FiRMASI ÖRNEĞi)}

\section{ÖZET}

Amaç- Firmalar oluşan piyasa koşullarında rekabet edebilmek amacıyla depolama, sevkiyat ve diğer ihtiyaçlara uygun kaliteli hizmet vermek ve çalışanların, ürünlerin güvenliğini sağlamak zorundadırlar.

Yöntem- Bu çalışmada; kargo sektöründe uygulanabilecek uygulamaları test ederek, risk analizleri oluşturup, bu sonuçlara göre iş sağlığı ve güvenliği analizinin gerekliliği ve önemini vurgulamak hedeflenmiştir.

Bulgular- Yükleme ve indirme işlemleri sırasında indirme ve yükleme rampasında çalışanların düşme ve ham maddenin paletli rampalara yükleme işlemi sırasında ya da sonrasında devrilme riski bulunmaktadır. Ayrıca yükleme ve indirme işlemleri yapılırken bu çalışmalar sırasında iş ve iş̧̧ güvenliği açııından gerekli önlemler alınmadığı takdirde çalışana ve depolanan ürünlere zarar vermektedir.

Sonuç- Riskler dikkate alındığında kargo firmaları risk analizi yaptırarak tehlikeleri ve aksaklıkların ortaya çıkmasını sağlamalıdır. Bu belirlenen risklerden korunmak amacıyla isG ile ilgili eğitimlerin düzenli olarak verilmesi ve uygulanması gerekmektedir. Dönemsel olarak belli aralıklarla yapılan bu değerlendirmeler sonucunda kargo firmalarında can ve mal kaybı azalarak, gerek maddi gerekse manevi kayıp azalacaktır.

Anahtar Kelimeler: İ̧̧ sağlığı ve güvenliği, kargo, risk değerlendirmesi, taşıma, depolama.

JEL Kodları: I10, I11, L00 


\section{Giriş}

Ülkemizde yürürlüğe giren 6331-4857 sayılı kanun ve yönetmeliklerin getirdiği yeniliklerle birlikte; pek çok sektörde olduğu gibi Kargo sektöründe de iş Sağlığı ve Güvenliği büyük önem taşımaktadır. Gelişen teknolojiyle birlikte çalışanlar, daha önce karşılaşmadıkları veya farkına varmadıkları yeni risk ve tehlikelerle karşı karşıya kalmaktadırlar. Her geçen gün iş kazalarıyla maddi ve manevi kayıpların büyük boyutlara ulaşması konunun önemini günümüzde daha da arttırmaktadır. Bugünün şartlarında kargolama; ürün, hizmet ve insan gibi kaynakların, ihtiyaçlarına cevap vermek amacıyla istenilen zamanda, istenilen yere ulaştıııması için bir araç olarak kullanılmaktadır. Kargolama, nakliye, malzeme idaresi, ambalajlama ve depolama gibi bilgilerin birleştirilmesini kapsar. Firmalar oluşan piyasa koşullarında rekabet edebilmek amacıyla depolama, sevkiyat ve diğer ihtiyaçlara uygun kaliteli hizmet vermek ve çalışanların, ürünlerin güvenliğini sağlamak durumundadırlar.

Gelişen teknoloji ve küreselleşme ile birlikte, taşımacılık sektörü de giderek önem kazanmıştır. Taşıma, sadece insanları değil aynı zamanda mal ve eşya ile haberin de coğrafi yer değişimini mümkün kılan bir faaliyettir. Taşıma sektöründe, üretim söz konusu olmasa da birçok üretim sektörünün verimliliği üzerinde etkiye sahip olan, birçok yan sektörün gelişmesine ve yeni istihdam olanaklarının oluşmasına katkı sağlayan emek yoğun bir hizmet sektörüdür (Anonim 1, 2018). Kargo firmaları genel olarak depolama, sevkiyat taşıma gibi faaliyetleri yürüterek hizmet verirler. Hammadde ya da yarı mamuller ilk aşamada rampalar kullanılarak araçlardan indirilme ya da yükleme işlemi yapılmaktadır. Yükleme ve indirme işlemleri yapılırken bu çalışmalar sırasında iş ve iş̧̧i güvenliği açısından gerekli risk değerlendirme ve analiz önlemleri alınmadığı takdirde çalışana ve depolanan ürünlere büyük zararlar verebilmektedir.

Riskler dikkate alındığında kargo firmaları risk analizi ve değerlendirmesi yaptırarak tehlikeleri ve aksakııkarın ortaya çıkmasını sağlamalı ve belirlenen risklerden korunma-önleme sağlayarak iş sağlığı ve güvenliği ile ilgili eğitimlerin düzenli olarak verilmesi ve uygulanması gerekmektedir. Belli düzenli aralıklarla yapılan bu değerlendirmeler sonucunda kargo firmalarında can ve mal kaybı azalarak, gerek maddi gerekse manevi kayıplar minumum seviyeye inecektir. Bu çalışmayla; kargo sektöründe uygulanan faaliyet uygulamalarını test ederek, risk değerlendirme ve analizlerini oluşturup, bu sonuçlar doğrultusunda iş sağlığı ve güvenliğinde risk dğerlendirme ve analizinin gerekliliği ve önemi vurgulanmak istenmiştir.

\section{LITERATÜR INCELEMESI}

Kargo taşımacılı̆̆ı ise taşımacılık sektörünün içinden gelişerek başlı başına bir sektör haline gelmiştir. Teknoloji ile bilgiyi birleştiren kargo firmaları, küreselleşen dünya ekonomisine ayak uydurarak kargo taşımacılı̆ıını gelişmesine katkıda bulunmuşlardır. Kargo taşımacılığı, genel olarak "belirli bir sürede şehir içi, şehirlerarası ya da ülkeler arasında eşya ve emtia taşınması" şeklinde tanımlanmaktadır. Kargo sektörüne ilişkin yasal düzenleme 4925 sayılı Karayolu Taşıma Kanunu olup, bu kanunda kargo ve kargo işletmeciliği tanımlarına yer verilmiştir (Anonim1, 2018).

Lojistik (fiziksel dağıtım) konuları müşteri hizmetleri, stok kontrolü, koruyucu paketleme, sipariş işleme, nakliye, depo yeri seçimi ve depolama gibi unsurları barındırmakta olup içerik itibariyle geniş bir alana sahiptir (Boone ve Kurtz, 1992). Ticarette yaşanan gelişmeler ve yoğun rekabet ortamı, günümüzde işletmeleri stratejik ortaklık kapsamında tedarik zinciri oluşturacak şekilde örgütlenmeye yöneltmiştir. Bu durum, lojistik faaliyetlerin nitelik ve niceliğini değiştirmiştir. Bu değişiklik, hissedar değerini maksimum kılma (en çoklama) amacı doğrultusunda, müşteri tatmini ve rekabet avantajı sağlamaya yöneliktir. Bu amaç doğrultusunda, işletme gelirlerinin dolayısıyla, nakit girişlerinin artması beklenmektedir. Ancak her faaliyetin olduğu gibi, lojistik faaliyetlerin de bir maliyeti vardır. Lojistik faaliyetlerin nitelik ve niceliğindeki değişiklikler, lojistik faaliyetlerin maliyetlerini artırmıştır. Yapılan çalışmalar, günümüzde lojistik maliyetlerin işletmenin toplam maliyetleri içinde önemli bir yer tuttuğunu göstermektedir. Lojistik maliyetlerdeki artış, işletmelerin finansal performansını, nakit akışlarını ve hissedar değerini olumsuz yönde etkilemektedir. Bu durum, lojistik faaliyetlerin ve bu faaliyetlerin yol açtı̆̆ maliyetlerin yönetim ve kontrolünü zorunlu hale getirmiştir. Günümüz ekonomik şartlarında işletmelerin lojistik maliyetlerden kurtulma olanağı bulunmamaktadır. Ancak lojistik süreçte optimum maliyetlerle (en uygun maliyet bileşenleri) olabildiğince yüksek müşteri tatminine ulaşmak mümkündür. Bunun için, lojistik faaliyetler ile maliyetlerin ayrıntılı bir şekilde analiz edilip yönetilmesi gerekmektedir. Lojistik maliyetlerin etkin yönetimi, işletmelerin finansal performansına katkı sağlayarak hissedar değeri üzerinde olumlu etki yaratacak unsurlardan biridir (Tokay ve diğ., 2010).

Çalışanlara en yüksek sağlık ortamını sunarak çalışma koşullarının olumsuz etkilerinden korunmasını sağlamak, iş ve işçi arasından mümkün olan en iyi uyumu sağlamak, iş yerindeki riskleri tamamen ortadan kaldırmak ya da zararları en aza indirebilmek, oluşabilecek maddi manevi zararları ortadan kaldırmak ve çalışma verimini arttırmaktır.

Kazaların oluşma nedenleri konusunda bilgisiz olunması, kazalara karşı korunmada eğitim eksikliği, yapılan iş konusunda deneyimsizlik gibi faktörler de kazaların oluşmasında önemlidir (Erkal ve Şafak 1998). Eğitimsizlik kaza nedeni ise, kişilerin genel ve mesleki eğitimlerinin arttırılması; aşırı yorgunluk kaza nedeni ise, kişilere yeterli dinlenme olanağı verilmesi gibi yaklaşımlar kazaların önlenmesi bakımından önemlidir (Bilir ve Yıldız, 2004). Kazalardan korunma çalışmaları insan hayatını korur, iş görmezliği önler, sigorta tazminatları ve işe devamsızlığı azaltır, verimliliği arttıır (Erkal ve Şafak, 1998). iş kazası sonucu oluşan zararları ortadan kaldırmak için yapılması gereken giderlerin, bu kazaları önlemek üzere yapılacak giderlerden çok daha yüksek olduğunun anlaşılması, günümüzde iş kazalarına karşı alınacak önlemlerin önemini daha da artırmıştır (Ünsar, 2004).

Risk değerlendirme, riski ortadan kaldırmak ya da kabul edilebilir seviyeye çekebilmek için tehlikelerin değerlendirilmesi yöntemi olup ortaya çıkabilecek olayın sonuçları ve bu sonucun gerçekleşme olasılığı dikkate alınmalıdır. Risk analizlerinin yapılmasında ilk olarak daha önce gerçekleşen kazaların verileri kayıtlı değil ise kayda geçirilmelidir. Kazanın olduğu yer, nasıl olduğu, nerede olduğu, neden olduğu, kullanılan ekipman, ne zaman olduğu, kim tarafından yapıldığı verileri kayda geçirilmelidir. Risk analizleri yeni yapılmaya başlanıyorsa çalışma alanlarının kontrolü ile risk analizleri başlatılmalıdır (Erdal ve diğ., 2008). 


\section{VERI VE YÖNTEM}

Risk değerlendirme çalışması, işletmelerin çalışma koşulları ve iş adımlarından dolayı oluşabilecek iş kazalarının ve meslek hastalıklarının tespiti için ihtiyaç duyulan önemli bir uygulamadır. İşçilerin sağlığı ve iş güvenliği için mevcut tehlikelerin tespit edilmesi, tehlikelerin giderilmesi ve güvenli bir çalıșma ortamının sağlanabilmesi için risk değerlendirme gerekli olan bir çalıșmadır. Risk değerlendirme çalıșması için çok farkı yöntemler bulunmaktadır. Her yöntem her işletmenin risk analizi için uygun olmayabilir. Amaç, işletmeye en uygun risk değerlendirme metodunun tespit edilip uygulanmasıdır. Ana kütle olarak tüm lojistik işlemlerin yürütüldüğü ve asıl işi lojistik olan ve lojistik dışında başka bir odağı bulunmayan bir firma (Balnak Lojistik) seçilmiştir. Bu seçimde araştırmanın yapıldığı firmada lojistik işlemlerin tümünün yürütülüyor olması, iş kazalarının tüm detayının arşivleniyor olması, yapılan risk analizlerinin, aksiyonların ve bu aksiyonların sonuçlarının, iş güvenliği uygulama bulgularının rapor ediliyor olması önemli bir etkendir.

Yapılan istatistikler, meydana gelen iş kazalarının kolaylıkla önlenebilir mahiyette olduğunu, ancak bir etüt ve metotlu planlı bir risk analizi çalışmaları ile önlenebileceğini göstermeştir. Yapılacak olan risk değerlendirilmesinin işlem basamakları olarak; önce tehlikelerin belirlenmesi sağlanır, risklerin değerlendirilmesi ile kontrol tedbirlerine karar verilir ve nihayetinde uygulanır. Tedbirlerin izlenmesi, kontrol edilmesi ve gözden geçirilmesi faaliyetleri kesintisiz yapılmalıdır. Bu hali ile sürekli bir döngü olarak sistem işlemektedir. Bu döngü ile tüm risk ve tehlikeleri kaynağında yok ederek olacak veya olması muhtemel tüm kazalar önlenmiş olur.

İ̧ sağlığı ve iş güvenliğine uyum sağlamayan araç-gereçler, acil çıkış kapıları, yangın söndürme mekanizmaları, elektrik panoları, forklift, elektrik kabloları, zemin, atık palet deposu, istifleme, depolama raflarındaki uygunsuz durumlar belirlenmiştir. Belirlenen tehlikeli ve uygunsuzluklar risk tablosu oluşturularak sınıfına göre derecelendirilip hangi önlemlerin alınması gerektiği düzenlenen tablolarla birlikte verilmiştir.

\section{BULGULAR}

Aşağıdaki Şekil 1'de yangın söndürme merkezlerinin önü paletlerle ve boş kutularla kapatıldığı gözlemlenmiştir. Gerekli önlemler için risk tablosu (Tablo 1) ve öneri belirlenmiştir.

\section{Şekil 1: Yangın Söndürme Sistemleri}

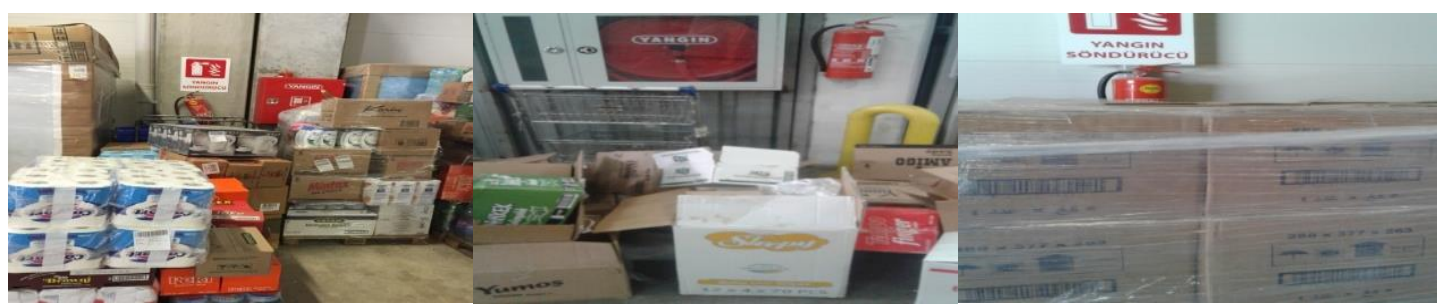

Tablo 1: Yangın Söndürme Sistemleri Risk Analizi

\begin{tabular}{|l|l|c|c|c|c|}
\hline \multirow{2}{*}{ TEHLiKE } & \multirow{2}{*}{ RiSK } & \multicolumn{3}{|c|}{ RISK DEĞERLENDIRME } & \multirow{2}{*}{ ÖNCELiK SIRASI } \\
\cline { 3 - 5 } & & OLASILIK & ŞiDDET & RiSK & \\
\hline Yangın & Yangına Müdahalenin Zorlaşması & $\mathbf{3}$ & $\mathbf{4}$ & 12 & $\mathbf{2}$ \\
\hline
\end{tabular}

Şekil 2'de palete sarılmış olan ürünler ve boş paletlerin özen gösterilmeden istiflendiği gözlemlenmiştir. Gerekli önlemler için risk tablosu ve öneri belirlenmiştir.

\section{Şekil 2: Yanlış İstifleme Örneği}

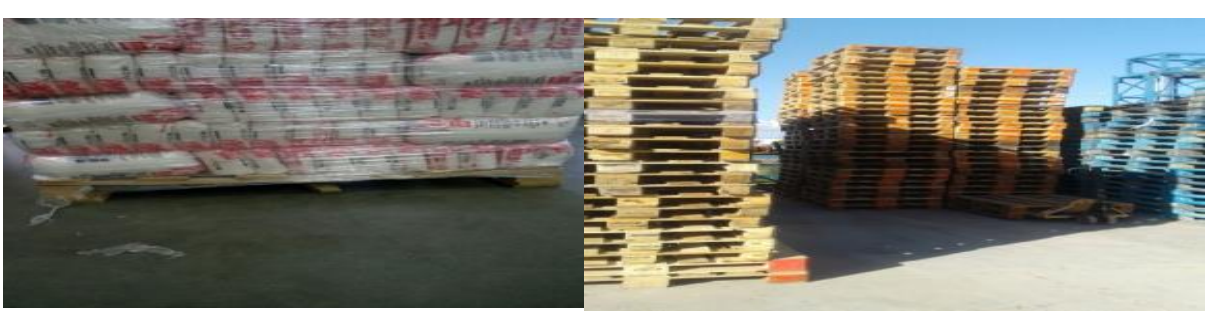

Tablo 2: Yanlış İstifleme Risk Analizi

\begin{tabular}{|l|l|c|c|c|c|}
\hline \multirow{2}{*}{ TEHLiKE } & \multirow{2}{*}{ RiSK } & \multicolumn{3}{|c|}{ RiSK DEĞERLENDIRME } & \multirow{2}{*}{ ÖNCELiK SIRASI } \\
\cline { 3 - 5 } & & OLASILIK & ŞiDDET & RiSK & \\
\hline Devrilme & Çalışanın üstüne devrilmesi & $\mathbf{2}$ & 5 & 10 & 2 \\
\hline
\end{tabular}

Şekil 3'de yoğun çalışmadan dolayı zeminin özelliğini kaybederek kayganlaştı̆̆ı görülmektedir. Gerekli önlemler için risk tablosu ve öneri belirlenmiştir. 


\section{Şekil 3: Kaygan Zeminde Forklift Çalışması}

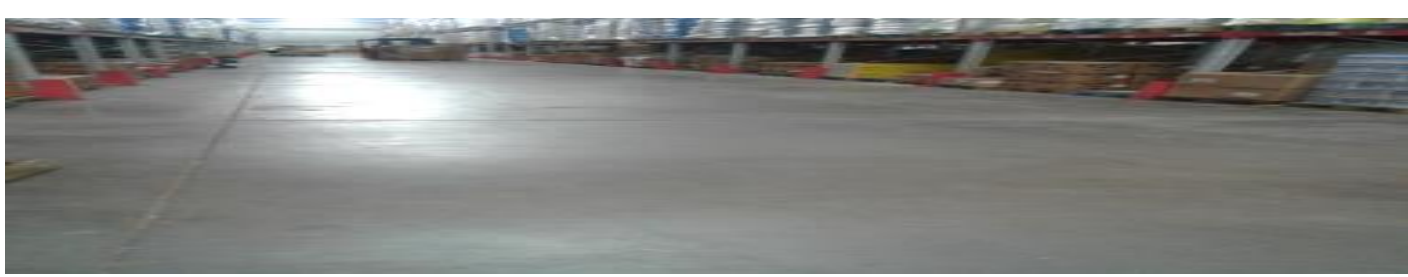

Tablo 3: Kaygan Zemin Risk Analizi

\begin{tabular}{|l|l|c|c|c|c|}
\hline \multirow{2}{*}{ TEHLiKE } & \multirow{2}{*}{ RiSK } & \multicolumn{3}{|c|}{ RiSK DEĞERLENDiRME } & \multirow{2}{*}{ ÖNCELIK SIRASI } \\
\cline { 3 - 5 } & & OLASILIK & ŞiDDET & RISK & \multirow{3}{*}{} \\
\hline Kaygan Zemin & Düşme Kayma & $\mathbf{2}$ & $\mathbf{3}$ & $\mathbf{6}$ & $\mathbf{3}$ \\
\hline
\end{tabular}

Şekil 4'te çalışanların kişisel koruyucu donanımları kullanılmadığı gözlemlenmiştir. Gerekli önlemler için risk tablosu ve öneri belirlenmiştir.

Şekil 4: Baretsiz ve Yüksekte Koruyucusuz Çalışma
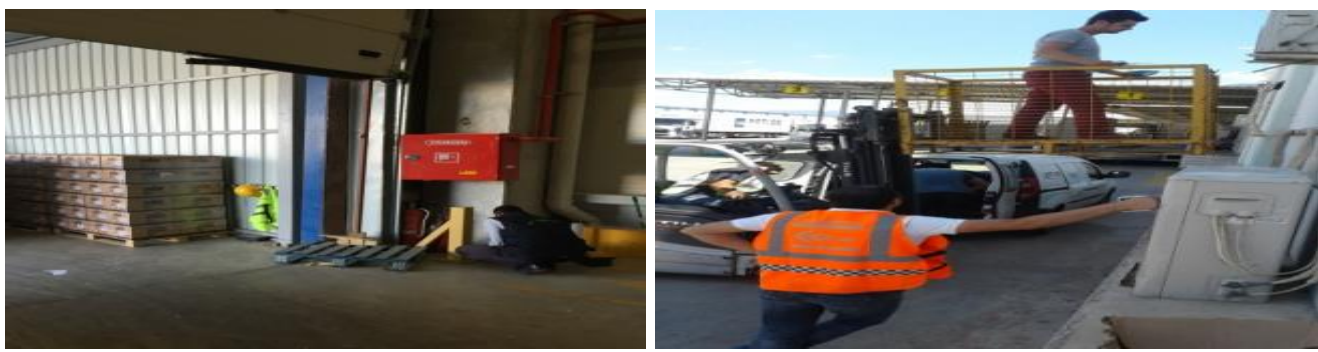

Tablo 4: Baretsiz ve Yüksekte Koruyucusuz Çalışma Risk Analizi

\begin{tabular}{|l|l|c|c|c|c|}
\hline \multirow{2}{*}{ TEHLiKE } & \multirow{2}{*}{ RiSK } & \multicolumn{3}{|c|}{ RISK DEĞERLENDIRME } & \multirow{2}{*}{ ÖNCELIK SIRASI } \\
\cline { 3 - 5 } & & OLASILIK & ŞIDDET & RiSK & \\
\hline Yaralanma Ve Düşme & Yaralanma Ve Düşme & $\mathbf{2}$ & $\mathbf{7}$ & 14 & $\mathbf{2}$ \\
\hline
\end{tabular}

Şekil 5’te görüldüğü gibi raf istifi sırasında kırık ve bakımsız paletlerin kullanıldığı gözlenmiştir. Gerekli önlemler için risk tablosu ve önerisi belirlenmiştir.

\section{Şekil 5: Kırık ve Bakımsız Palet}

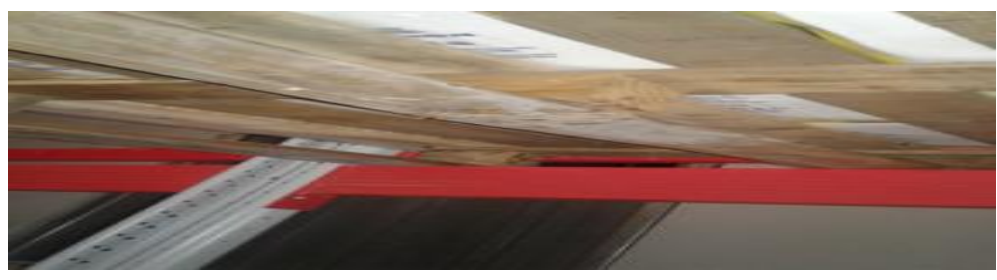

Tablo 5: Kırık ve Bakımsız Palet Risk Analizi

\begin{tabular}{|l|l|c|c|c|c|}
\hline \multirow{2}{*}{ TEHLiKE } & \multirow{2}{*}{ RiSK } & \multicolumn{3}{|c|}{ RISK DEĞERLENDIRME } & \multirow{2}{*}{ ÖNCELiK SIRASI } \\
\cline { 3 - 5 } & & OLASILIK & ŞiDDET & RiSK & \\
\hline Devrilme Ve Yaralanma & Devrilme Ve Yaralanma & 3 & 5 & 15 & 1 \\
\hline
\end{tabular}

\section{SONUÇ}

Yapılan risk analiziyle Tablo 1'deki sonuca göre risk derecesi 12 yani orta seviye bir risk grubundadır. Öncelik sırası 2'dir. Ortaya çıkan risklerin önlenmesi için yangın söndürme sistemlerinin çevresinin açık olması gereklidir. Gerek duyulduğunda rahat ulaşılabilmelidir. Tablo 2'e göre risk derecesi 10 yani orta seviye bir risk grubundadır. Öncelik sırası 2'dir. Ortaya çıkan risklerin önlenmesi için paletler düzgün istiflenmeli gerekirse koruyucu bir raf sisteminde muhafaza edilmelidir. Bunun yanı ürünlerin palete iyi istiflenmiş olması gerekir ve ambalajının sağlam yapılması gereklidir. 
Tablo 3'e göre risk derecesi 6 yani düşük seviye bir risk grubundadır. Öncelik sırası 3'tür. Ortaya çıkan risklerin önlenmesi için kayma tehlikesi olan bölgelere gerekli kaydırmazlık ekipmanlarının yerleştirilmesi veya zeminin tekrardan tadilat yapılması gereklidir.

Tablo 4'e göre risk derecesi 14 yani yüksek seviye bir risk grubundadır. Öncelik sırası 2'dir. Ortaya çıkan risklerin önlenmesi için çalışanlara kişisel koruyucu donanımlarla ilgili eğitim verilmeli ve gerekli koşullarda kesinlikle kullandıılmalıdır. Tablo 5'ye göre risk derecesi 15 yani yüksek seviye bir risk grubundadır. Öncelik sırası 1'dir. Ortaya çıkan risklerin önlenmesi için raf istifi yapılırken kırık ve hasarlı paletler tespit edilerek yenileriyle değiştirilmelidir ya da gerekli kurallar doğrultusunda tamiri yapılmalıdır. Ayrıca kaldırma araçlarının (vinç, ceraskal, forklift vb.) rutin olarak Makine Mühendisleri Odası tarafından kontrol testlerinden geçirilerek makinelerden kaynaklı olası iş kazaları riski en aza indirilmesi gerekmektedir. Ayrıca kaldırma taşıma araçlarının (vinç, ceraskal, forklift, konveyör vb.) rutin olarak Makine Mühendisleri Odası tarafından kontrol testlerinden geçirilerek makinelerden kaynaklı olası iş kazaları riski en aza indirilmesi gerekmektedir.

\section{KAYNAKLAR}

Anonim 1 (2018). https://www.csgb.gov.tr/media/6067/2015 80.pdf (Erişim Tarihi: 08.06.2018).

Bilir, N., Yıldız, A. N. (2004). İş sağliği ve güvenliği. Hacettepe Üniversitesi Yayınları, Ankara.

Boone, L. E., Kurtz, D. L. (1992). Contemporary marketing. The Dryden Press International Edition, 7th Edition, P:492- 513.

Erkal, S., Şafak, Ş. (1998). Ev idaresi hizmetlerinin yürütülmesinde karşilaşilacak kazalar ve önlemler. I. Ulusal Kurum Ev İdaresi Kongresi 2123 Ekim, Ankara.

Erdal, M., Görçün, Ö. F., Görçün, Ö., Saygıll, M. S. (2008). Entegre lojistik yönetimi. Beta Yayınları, s. 578- 595.

Tokay, S. H., Deran, A., Arslan, S. (2010). Lojistik maliyet yönetiminde izlenebilecek stratejiler ve muhasebe eğitiminden beklentiler. Dumlupınar Üniversitesi, Sosyal Bilimler Dergisi, Sayı: 29.

Ünsar, A. S. (2004). İ̧ kazalari ve örgütsel verimlilik. Verimlilik Dergisi sayı: 3, S.89-101. 